\title{
Editorial First Issue
}

With this first issue, we are very pleased to announce the launch of the International Journal of Hybrid Intelligent Systems. The area of hybrid intelligent systems became an attractive research area in the early 90 's and has been continuously growing in interest since then. It was recently felt that the increasing number of people in the hybrid intelligent systems community needs a journal for the publication of their research outputs.

The International Journal of Hybrid Intelligent Systems (IJHIS) aims to address this need and to be the main international forum for publishing papers on hybrid and integrated intelligent techniques and applications. The journal intends to primarily publish papers which combine or integrate different intelligent methodologies and approaches in various real-world applications.

The IJHIS will be published quarterly. The abstracts of the published papers, and sometimes the full papers, will be available on-line on the journal web site: http://ijhis.hybridsystem.com/. The journal will contain original research papers on the topics listed in "Aims and Scope". Each paper will be thoroughly reviewed by 3 independent reviewers. In addition, the journal may occasionally contain special issues on various topics on hybrid intelligent systems, book reviews, conference reports, letters to the editors, conference announcements, etc.

Thanks are due to many people who have helped in starting up this new journal. We are particularly grateful to the Regional (Associate) Editors who provided us with a lot of support and advice, and who will continue to represent the journal in their geographical areas. We are sure that their international reputation and great expertise in the field will have a significant contribution in shaping up the journal and making IJHIS a prestigious first-class international journal.

It is also our great pleasure to welcome the members of the extensive Editorial Board of IJHIS. We rely on their expertise for reviewing and accepting papers to the journal. Therefore their contribution to the journal is invaluable and we are grateful to them for giving freely of their time to review papers for the journal. We hope they will continue to help us in the future.

We are convinced that with this unreserved support from such a prominent and large team of researchers, the IJHIS will become one of the most prestigious journals in the general area of intelligent systems. We are fortunate to work with this team.

Finally, the Editors-in-chief wish to thank the authors who submitted papers to the first issue of IJHIS. We are grateful that they responded to our invitation. Many thanks are due to the members of the Editorial Board who reviewed these first papers submitted to the journal. We thank them for their precious feedback and advice.

We hope that the new International Journal of Hybrid Intelligent Systems will serve the HIS community well and this journal will be the main vehicle of presenting ideas and research work in the area. Any suggestion on how to improve our activity in order to deliver a better journal to the authors, readers and subscribers of this journal will be always very much appreciated. 